\title{
Profuse Upper GI Bleeding Secondary to Eosinophilic Esophagitis
}

\author{
Emrah Aydin, ${ }^{*}$ Ömer Faruk Beşer ${ }^{2}$ \\ 1 Department of Pediatric Surgery, Bahcelievler State Hospital, Turkey \\ 2 Department of Pediatric Gastroenterology, Okmeydani Education \& Training Hospital, Istanbul, Turkey
}

\begin{abstract}
Eosinophilic esophagitis is a chronic disease with immunoallergic etiology. In this condition infiltration of the esophagus with eosinophils, results in esophageal dysfunction. A sixteen years old girl was admitted to the emergency department with profuse hematemesis. Patient needed multiple blood transfusions. Endoscopy ruled out surgical causes of upper Gl bleed and esophageal punch biopsy revealed eosinophilic esophagitis. Patient responded well to anti-allergic treatment.
\end{abstract}

\section{Key words: Eosinophilic esophagitis; Gastrointestinal (GI) hemorrhage; Children}

Correspondence*: Emrah AYDIN, Department of Pediatric Surgery, Bahcelievler State Hospital, Turkey

E-mail: dremrahaydin@yahoo.com @ (C) 2017, Aydin et al.

Submitted: 24-04-2017

Accepted: 18-06-2017

Conflict of Interest: None

Source of Support: Nil

This is an open-access article distributed under the terms of the Creative Commons Attribution License, which permits unrestricted use, distribution, and reproduction in any medium, provided the original work is properly cited.

\section{INTRODUCTION}

Eosinophilic esophagitis (EoE) is one of commonest causes of chronic and recurrent esophagitis. It rarely presents with profuse Gl bleeding. At the time of diagnosis patients can have myriad of lesions like edema, exudate, furrows, and stricture of the esophagus.[1,2] Herein, we report an adolescent girl who presented with profuse upper Gl bleeding.

\section{CASE REPORT}

A 16-year-old girl presented to the emergency department with hematemesis. This was the first episode. On examination her heart rate was 145 /minute and blood pressure $110 / 70 \mathrm{mmHg}$. Laboratory investigations showed hemoglobin of $9 \mathrm{~g} / \mathrm{dL}$, hematocrit $27.1 \%$, platelets $340000 \mathrm{~mm} 3$. Clotting profile was normal. On nasogastric intubation, bright red fresh blood was noted. She was transfused with 7 units of packed cells and 5 units of fresh frozen plasma in first 48 hours. Proton pump inhibitors, antacids, antibiotics, etc. were added to the treatment. There was no portal hypertension on Doppler ultrasonography and CT splenoportography. She had minimal gastroesophageal reflux on upper Gl contrast imaging. An upper Gl endoscopy showed aphthous lesions at stomach and duodenum; esophagus was also erythematous (Fig.1). Multiple biopsies were taken at endoscopy. These were reported as eosinophilic esophagitis and chronic gastritis. Eosinophil values of the specimen were between 17-23/HPF at esophagus while 0$10 / \mathrm{HPF}$ at the stomach. She was followed up with a combination of proton pump inhibitor, antacid, antihistamines and a diet with avoidance of food allergens such as egg and milk. One month later, follow-up upper GI endoscopy showed healed aphthous lesions and complete recovery of esophagitis. After a month she was again admitted to the emergency department with melena. Repeat endoscopy showed mild esophageal hyperemia. History revealed poor drug therapy compliance. She was 
counseled and antihistamine therapy was reinstituted. At 6-month follow-up endoscopy was performed and esophageal biopsy showed reduction in eosinophil value (5-10/HPF). At the end of the first-year follow-up, antacid and antihistaminic treatment was stopped. She is asymptomatic at 2-year follow-up.

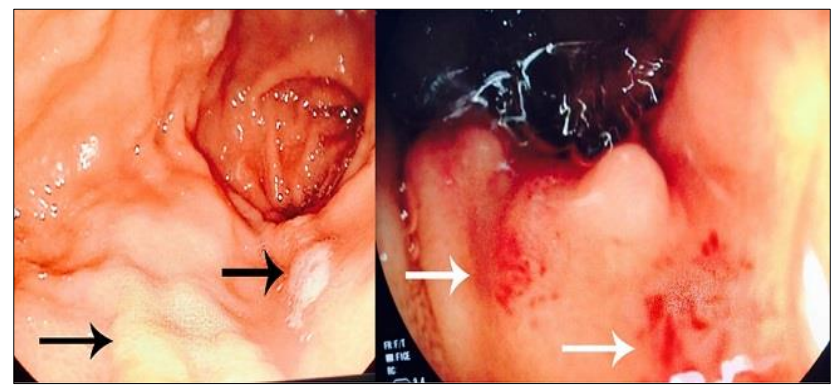

Figure 1: Aphthous lesions (black arrow) and hyperemia (white arrow) at upper GI endoscopy of the patient.

\section{DISCUSSION}

EoE has been widely recognized since the mid-1990s and is the most common reason of dysphagia both in children and adults.[2] The pathophysiology of this condition is not completely understood. EoE seems to be chronic immune and/or antigen-mediated disorder. It is speculated to be mediated by IgG4 not by IgE.[3] EoE can be triggered by food antigen or aero-antigen.[1] Although the index case did not have any atopic symptoms prior to admission, but discontinuation of antihistamines during active phase resulted in melena, indicating its immunological basis.

The final diagnosis was made on histopathology. Almost $1 / 3$ rd of the patients diagnosed as EoE have normal endoscopic findings. To diagnose EoE, eosinophil values should be $>15 /$ HPF in pathology specimen of the esophagus and the other parts of the GIT should not have eosinophilia. The criterion was fully met in the index case.

The treatment is aimed to diminish symptoms, prevent disease progression, improve the quality of life, and treat complications.[2] Our case is unique as she presented with massive upper Gl bleed which is very rare finding in EoE. Our patient had blood product replacement for the first 48 hours along with intravenous proton pump inhibitors, antacids, and antihistamine. There are reports regarding allergic and proton pump inhibitor-dependent subtypes of EoE. Most commonly used treatment modalities are proton pump inhibitors, topical or systemic steroids, anticlonal antibodies, and dietary modification. Proton pump inhibitors should be used for at least $8-12$ weeks for relief of the symptoms. [4,5] In the index case endoscopic findings resolved after a month but recurred following discontinuing of medication. She used antacids and antihistamine again for one year and got remission.

To conclude, EoE rarely presents with gastrointestinal hemorrhage. The unusual presentation of EoE should be kept in mind. Proper treatment and strict follow-up can prevent complications of the disease.

Consent: Authors have submitted signed consent form from legal guardians of the patient for use of clinical material in this manuscript. The Consent form is available with Editorial office.

Authors' Contribution: Both authors contributed equally in concept, literature review, and drafting of the manuscript. Both authors approved the final version of this manuscript.

\section{REFERENCES}

1. Muir AB, Merves J, Liacouras CA. Role of endoscopy in diagnosis and management of pediatric eosinophilic esophagitis. Gastrointest Endosc Clin N Am. 2016; 26:187-200.

2. Sodikoff J, Hirano I. Therapeutic strategies in eosinophilic esophagitis: Induction, maintenance and refractory disease. Best Pract Res Clin Gastroenterol. 2015; 29:829-9.

3. Gonzalez-Cervera J, Lucendo AJ. Eosinophilic esophagitis: An evidence-based approach to therapy. J Investig Allergol Clin Immunol. 2016; 26:8-18.

4. Gómez TE, Sánchez MP, Donado PP, Castro JA, Rodriguez SJ, Mendez DY, et al. Eosinophilic esophagitis: Demographic, clinical, endoscopic, histological and allergological characteristics in children and teenagers in a region of central Spain. J Investig Allergol Clin Immunol. 2017; 27:1-22.

5. Gülcan EM, Vitrinel A. Eozinofilik özofajit. Türk Pediatr Arşivi. 2010; 45:232-7.[Article in Turkish] 